\title{
1 On Some Problems of Estimating Fundamental Niche from Physiological Data
}

3 Gutiérrez-Ruelas Jesús Salvador ${ }^{(1)}$

4 Jiménez, Laura ${ }^{(4)}$

5 Quiroz-Reyes, Ana Patricia ${ }^{(3)}$

6 Sotelo-Pedroza, Sabrina Cherizar ${ }^{(3)}$

7 Soberon, Jorge ${ }^{(4)}$

8 (1) División de Ingeniería, Universidad de Sonora, Blvd. Luis Encinas y Rosales S/N,Col.

9 Centro Hermosillo, Sonora, México

10 (2) División de Ciencias Exactas y Naturales, Universidad de Sonora, Blvd. Luis Encinas

11 y Rosales S/N,Col. Centro Hermosillo, Sonora, México

12 (3) División de Ciencias Biológicas y de la Salud, Universidad de Sonora, Blvd. Luis

13 Encinas y Rosales S/N,Col. Centro Hermosillo, Sonora, México

14 (4) Department of Ecology and Evolutionary Biology and Biodiversity Institute, 15 University of Kansas, 1235 Jayhawk Blvd., Lawrence, KS, USA

\section{Abstract}

Hutchinson proposed the idea of the fundamental niche, determined by physiological properties of a species, more than 50 years ago. The idea remains both central to ecological thinking and largely unexplored experimentally. In this note, we describe some problems of using physiological experiments databases to estimate fundamental niches, show some solutions, and the apply our solution to testing the prediction that fundamental niches contain realized niches, for some species of marine fishes and terrestrial beetles. Our results were concordant with Hutchinson's predictions.

\section{Introduction}

27 In its modern form, the discipline called species distribution modeling (SDM) is based on the

28 estimation of limits of tolerance to environmental variables, or ecological niche modeling 29 (ENM) (Guisan \& Zimmermann, 2000; Peterson et al., 2011). There is a relationship between geographical regions and their environmental features, called "Hutchinson's Duality"

31 (Colwell \& Rangel, 2009) and this relationship enables estimating observed limits of 
32 tolerance in multivariate space, and then projecting them in geographical space, to obtain

33 estimates of distributions.

34 In practice all the above can be done by software ignoring most of the conceptual framework.

35 For instance, the package Maxent (Phillips, Anderson, \& Schapire, 2006) simply asks for: (i)

36 sets of coordinates of observations and, (ii) for sets of raster files representing environmental

37 variables, and it performs the calculations that characterize the occurrence points in the

38 multivariate environmental space. This is then are projected to geographic space. The entire

39 procedure can be performed without mentioning the term "niche" even once.

40

41

42

However, several niche concepts are central to the interpretation of the procedures and results of most software used to estimate distributions. The basic idea is that of fundamental niche. A fundamental niche is the set of environmental combinations that produce a population fitness capable of sustaining viable populations (Drake, 2015; Holt, 2009; Hutchinson, 1957; Peterson et al., 2011) in the absence of biotic interactions. This is essentially a physiological concept, abstract and theoretical. In symbols, if $f(v)$ is the function mapping environmental combinations into fitness, then the fundamental niche is $\mathbf{F}=\{\mathbf{v} \mid f(\boldsymbol{v})>0\}$. The fundamental niche was originally conceived by Hutchinson as a simple rectangle in the multivariate environmental space, but soon people started using other shapes, for instance, ellipsoids (Brown, 1984; Drake, 2015; Maguire Jr, 1973), which somehow imply a structure (the expression in fitness units of regions of tolerance and their covariances) of fitness in environmental space. The fundamental niche is what evolves. In other words, the limits of tolerance and the covariations among them is what can be inherited and selected by evolutionary processes. The fundamental niche then deserves its name.

Now, notice that different regions of the world, and at different times, may have different environmental combinations. Therefore, we need a second niche concept, an "existing" fundamental niche, an idea introduced very briefly by Hutchinson(1957) and then elaborated by Jackson and Overpeck (2000). The existing niche is the fundamental niche actually existing in a given region, and at a given time. If the environments in a region $\mathbf{M}$, at a time $t$ are symbolized by $\mathbf{E}(\mathbf{M}, t)=\{\mathbf{v} \mid \mathbf{v}$ exists in region $\mathbf{M}$ at time $t\}$ then the existing niche is 
$61 \mathbf{F}^{*}(\mathbf{M} t)=\mathbf{E}(\mathbf{M}, t) \cap \mathbf{F}$. The existing niche is the combination of the physiological limits of

62 tolerance expressed in a given region and time. It combines physiology with environment.

64 Finally, the environments in which a species can be observed are further limited by biotic interactions and by accessibility to movements. This defines the actual subset of the existing niche where a species can be observed. Any actual field observation will have to come from

67 the existing niche restricted by availability, interactions and movements. The resulting set of actually observed environments is called the realized niche, denoted by $\mathbf{R}(\mathbf{M}, t)$.

69 Hutchinson (1957) proposed a simple inequality relating the fundamental and the realized. Using the existing niche, and the symbols we defined above, the inequality is:

$$
\mathbf{F} \supseteq \mathbf{F}^{*}(\mathbf{M}, t)=\mathbf{F} \cap \mathbf{E}(\mathbf{M}, t) \supseteq \mathbf{R}(\mathbf{M}, t)
$$

Soberón \& Arroyo-Peña (2017) tested this inequality, but some of the subtleties of doing it were not well discussed. An extremely important question, the one we will explore here, is how can one combine physiological experimental data with climatic data, to establish the comparison in equation (1.1). This is by no means a simple operation (Addo-Bediako, Chown, \& Gaston, 2000; Angilletta Jr \& Angilletta, 2009; Bozinovic, Calosi, \& Spicer, 2011; Kearney \& Porter, 2009), mainly because physiological experiments are performed on simplified conditions, measuring variables that are not necessarily the ones that characterize environments in the field. To test equation (1.1) we will get data for the fundamental niches from a database of estimations of ranges of tolerance to extreme temperatures (Bennet et al.

81 2018), and data for the realized niches from occurrence reports, obtained from the Global 82 Biodiversity Information Facility (GBIF; (Robertson et al., 2014). The data required to estimate fundamental niches would be ideally derived from estimations 84 of fitness under factorial experimental design. This is a task very seldom attempted, with the usual handful of exceptions (Birch, 1953; Hooper et al., 2008). Following Soberon \& Arroyo-Peña (2017), we will use a single-variable (temperature) approximation to estimate

87 the fundamental niche. We know that this is a very coarse approximation, but there is simply no data available on multivariate niche measurements using experiments. Even our single variable approach has some problems that we will discuss below. 


\section{$91 \quad$ Methods}

92 The objective of the present work is to illustrate some of the problems of attempting to

93 relate temperature-tolerance data, obtained physiologically. To estimate fundamental niches

94 we obtained data on ranges of temperature tolerance from the database GlobTherm

95 https://datadryad.org/resource/doi:10.5061/dryad.1cv08/7 (Bennet et al. 2018). The ways

96 they report extremes vary considerably between taxonomic groups, and some ways were

97 unsuitable to estimation of fundamental niches. As examples, we included data from

98 mammals, beetles and fish. For mammals, the Thermal Neutral Zone is reported, which is a

99 range of temperature within which metabolic activity remains constant. This range is not

100 really a good measure of the fundamental niche. For the beetles and fishes, $100 \%$ mortality

101 lower and higher temperatures are reported. These are certainly compatible definition of a

102 fundamental niche.

103

104 We also obtained information about the realized niche from records of species' geographic occurrences. These were obtained from the Global Biodiversity Information Facility (GBIF;

106 http://www.gbif.org). Validation of the taxonomic name of each species was done through 107 consultation of The International Union for Conservation of Nature's Red List of Threatened 108 Species (IUCN; https:/www.iucnredlist.org/) as well as other available biodiversity 109 databases. We downloaded 1,739 points for mammals, 14,141 for fishes, and 3,558 for 110 beetles. We subjected the data to a cleaning process by removing data fields that were either 111 not relevant to our study or were incomplete or inconsistent (Costello \& Wieczorek, 2014).

112 This was done using Microsoft Excel and the R package 'dismo'. We filtered data for cases 113 with no georeference, occurrence records, repeated observations, records with no decimal 114 precision, switches between longitude and latitude, changes in sign of geographic coordinates 115 and using the program QGIS we were able to filter records outside the region of interest by 116 mapping the occurrences in a world map raster.

118 Once this was done, we extracted bioclimatic variables for each species coordinates from 119 WorldClim (https://www.worldclim.org). We used the annual mean temperature (bio1), 120 maximum temperature of warmest month (bio5) and annual precipitation (bio12) in the 
121 spatial resolution of 10 minutes $\left(\sim 340 \mathrm{~km}^{\wedge} 2\right)$ which we then used to create one single raster

122 file and then extracted the environmental values for each occurrence point using the $\mathrm{R}$

123 package 'raster.'

124

125 To create an estimate of the accessible region we used the World Wildlife Fund map of the 126 ecoregions of each continent (Olson et al., 2001)

127 https://www.arcgis.com/home/item.html?id=67e8c7ce18f744f0b0e067c1e2247b6c).

128 We extracted the ecoregion which matched the coordinates previously obtained for each 129 species. We then assigned names and a code for each ecoregion in order to facilitate the 130 manipulation of the data.

132 We then obtained a particular number of coordinates for both fish and beetles at random in 133 order to reduce the sampling bias. In the case of the beetles species, there was a large 134 difference between the number of samples found in the UK regions and the rest of the 135 European continent (Spain, Belgium and the Netherlands). In order to remedy this we took 1361000 samples at random from England and 1000 samples at random from the rest of the 137 continent, thus taking into account the sampling bias that would otherwise interfere with the 138 results. The same was done with the fish species.

140 We then used the gathered information with RStudio to fit a smooth histogram (a kernel 141 density) to make a model of realized niche as well as the temperature in the $\mathrm{M}$ area for each 142 species of fish and beetles. Hutchinson's hypothesis is that the range of the fundamental 143 would contain the observations (realized niche).

145 We also estimated the proportion of available environmental space that a particular species 146 uses, by estimating the integral of the minimum between the black and green curves (Soberon 147 \& Arroyo-Peña, 2017). 
151 The data on ranges of temperature tolerance obtained from the GlobTherm database were

152 very contrasting in concept and in methodology. We found that they were not adequate to

153 describe the fundamental niche in case of mammals, since GlobTherm reports a Thermal

154 Neutral Zone (Bennet et al. 2018) which represents a range where metabolic activity does

155 not change, therefore it encompasses an narrow and extremely favorable range, as we show

156 in Figure 1, a random example out of the 61 cases of mammals in the database. All examples

157 of mammals have very narrow TNZ ranges, often completely outside the actual observations.

158

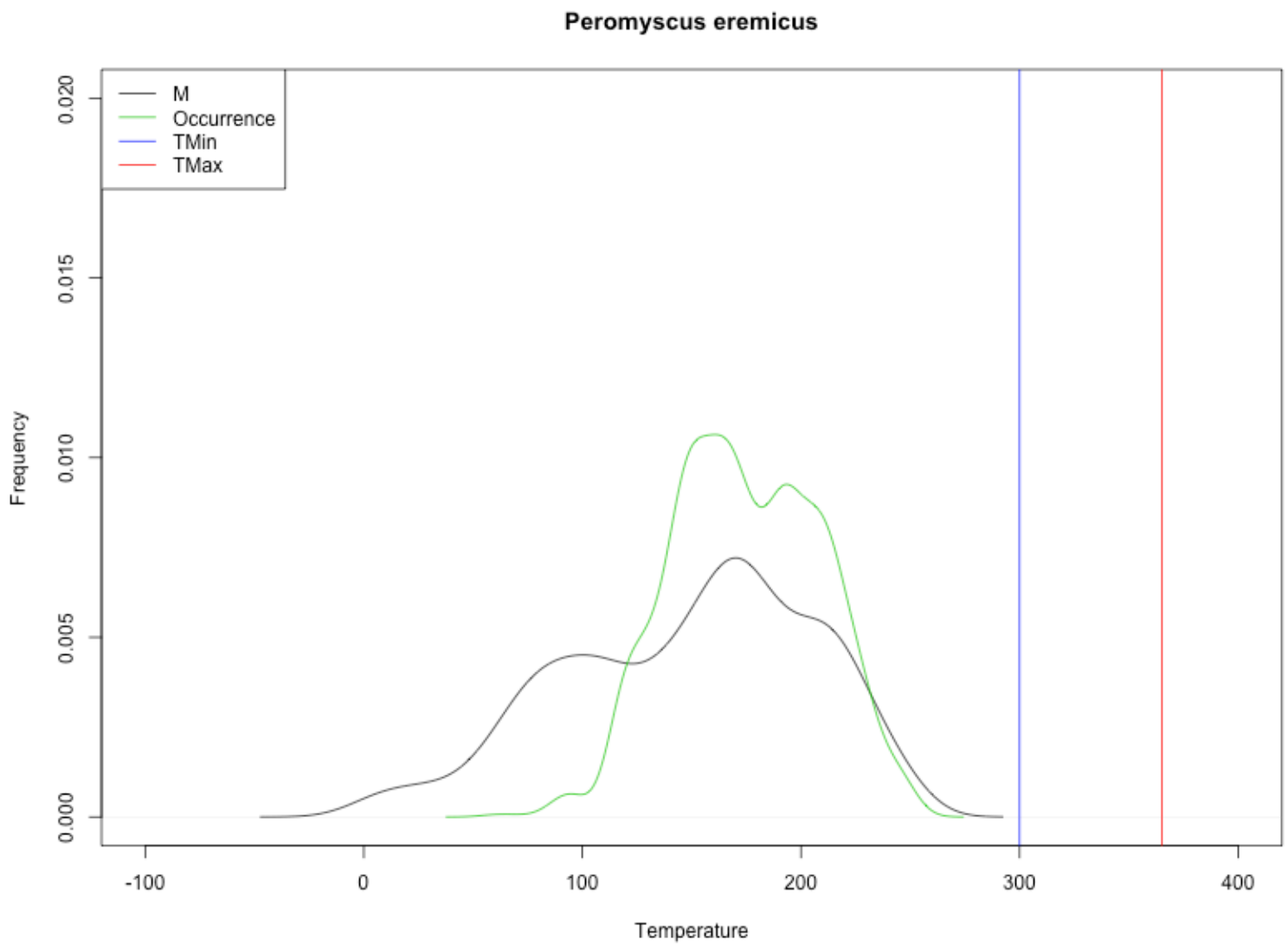

159

160 Figure 1. Range of Thermal Neutral Zone for one species of a desert mouse (blue and red

161 lines), the smooth histogram of the available mean yearly temperature (times 10: BIO1

162 bioclimatic variable) in the $\mathrm{M}$ zone for Peromyscus eremicus (black line), and the smooth 163 histogram of the GBIF observations (green line). 
165 On the contrary, the data on ranges of temperature tolerance obtained from GlobTherm

166 proved sufficient in the case of beetles and fish species, because these ranges are defined in

167 terms of $50 \%$ and $100 \%$ mortality. These are able to portray a reasonable model for the

168 fundamental niche for these species. In Figure 2 we present the data points used for the

169 marine species, and in figure 3 the data records for the beetle species.

170

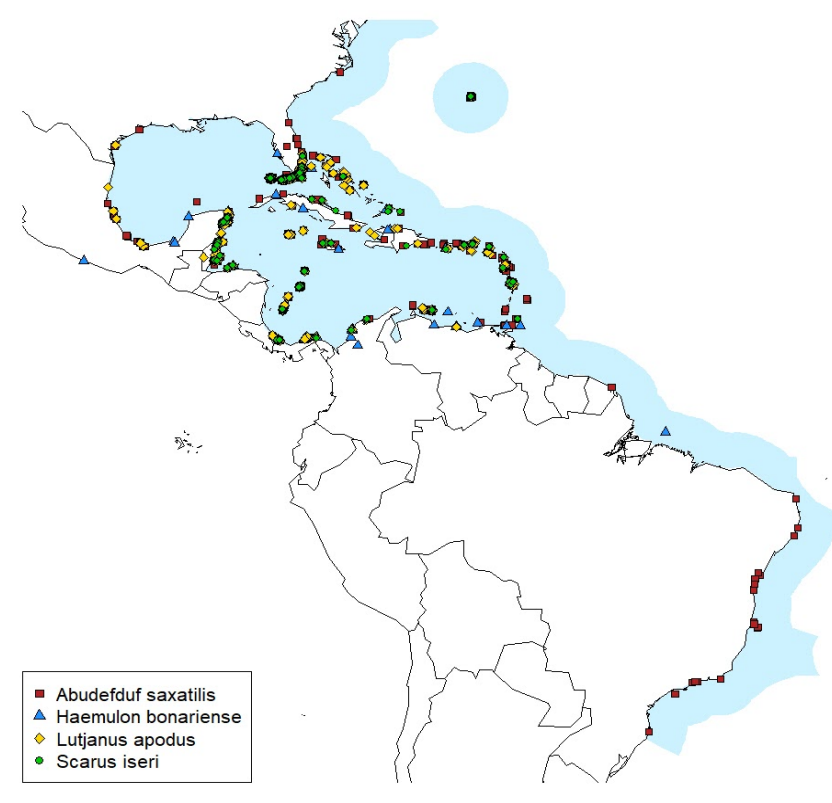

171

172 Fig. 2 Map of occurrences of the fish species Abudefduf saxatilis, Haemulon bonariense,

173 Lutjanus apodus and Scarus iseri along with the environmental availability region (M). 


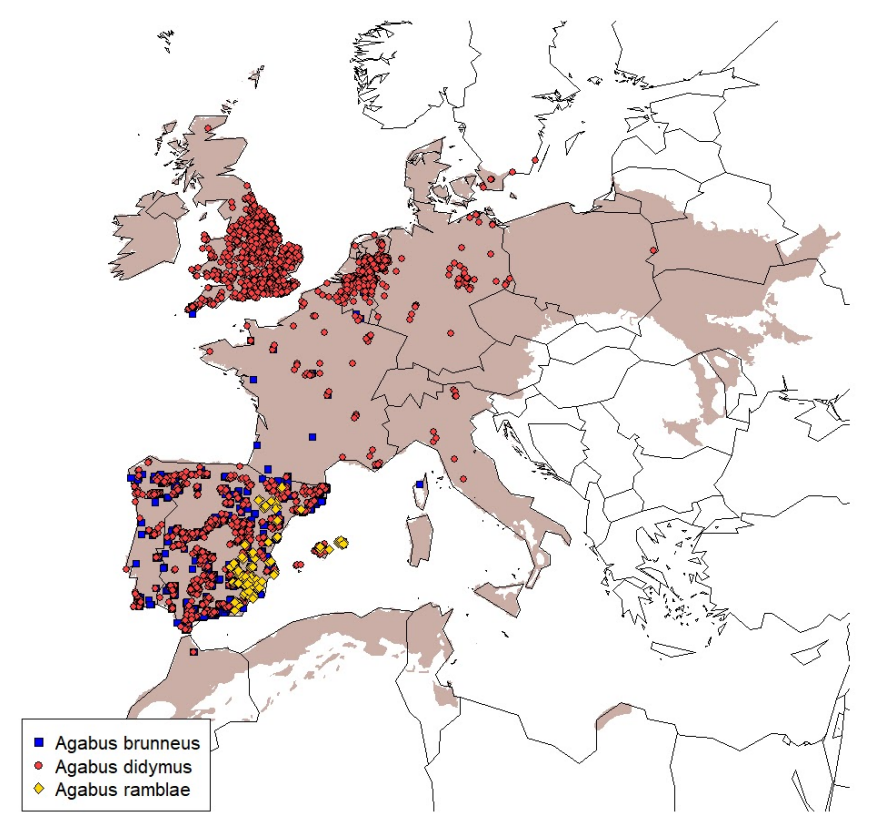

175

176

177

178

179

180
A

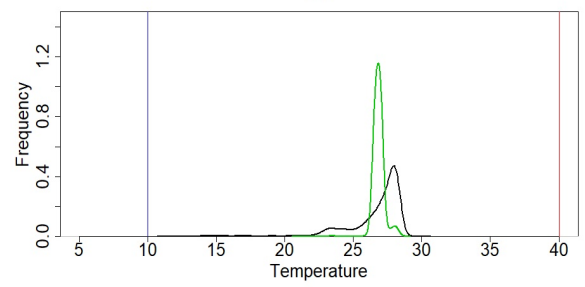

B

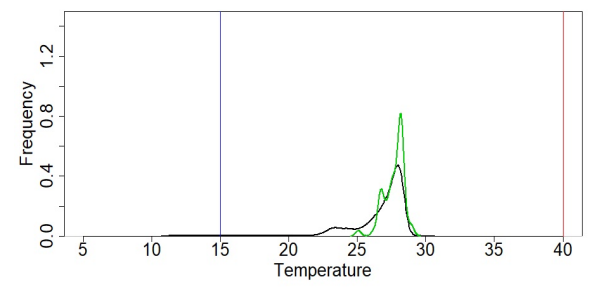

c

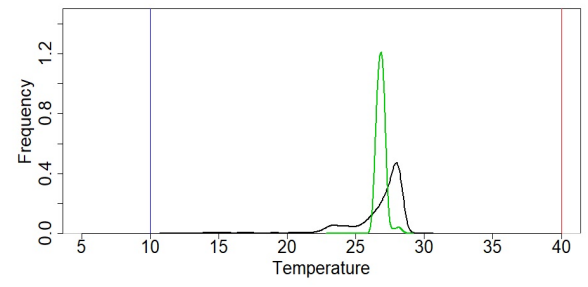

D

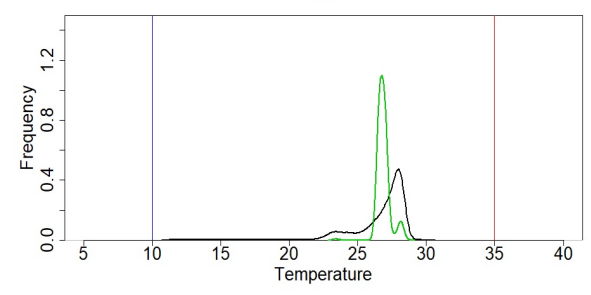

182 Figure 4. Graphs representing the fundamental niche, existent niche and realized niche of 183 the species of fish Abudefduf saxati (A), Haemulon bonar (B), Lutjanus apodus (C) and 184 Scarus iseri (D); where the maximum temperature (red) and minimum temperature (blue) 
constitute the fundamental niche, the environmental availability $\mathrm{M}$ is the black line, and the number of species occurrences (green) is the realized niche.
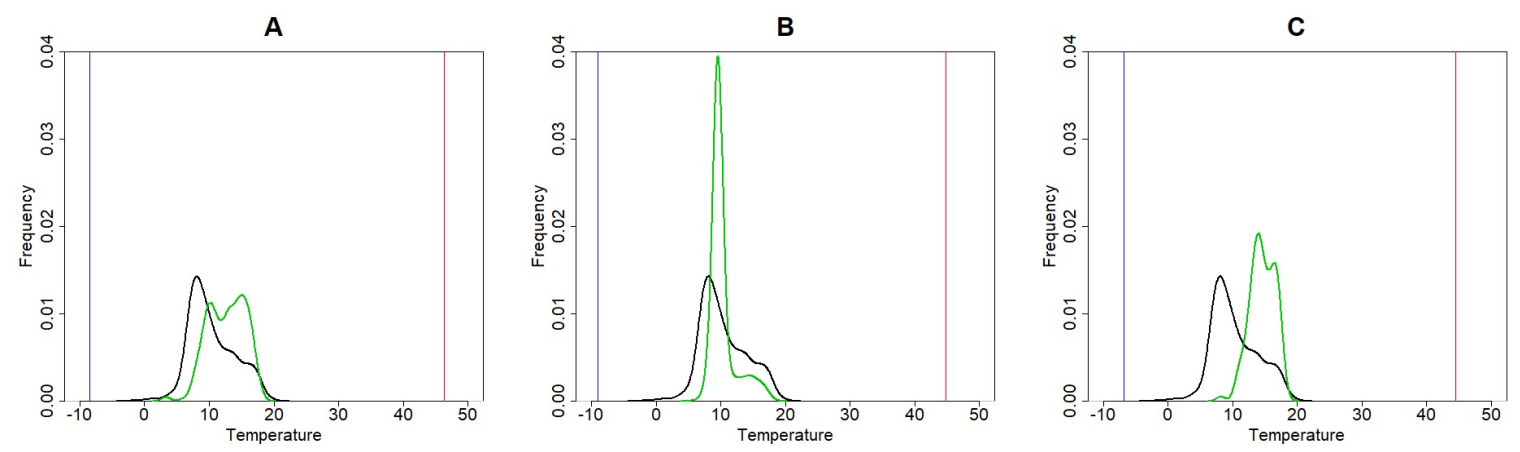

Figure 5. Graphs representing the fundamental niche, existent niche and realized niche of the species of beetle Agabus brunneus (A), $\underline{\text { A.didymus }}$ (B) and $\underline{\text { A ramblae }}$ (C); where the maximum temperature (red) and minimum temperature (blue) constitute the fundamental niche, the environmental availability $\mathrm{M}$ (black) is the environmental availability in $\mathrm{M}$ and the number of species occurrences (green) is the realized niche.

Finally, in table 1 we present the proportion of environmental space occupied by the species, as estimated from occurrences from the GBIF database.

\section{Discussion}

An important lesson from our results is that data of tolerance curves, even for the simplified case of a single variable, cannot be simply assumed to represent a fundamental niche in the sense of Hutchinson. Hutchinson (1957) defined the niche in terms of fitness, and unless the experiments have a direct relationship to fitness, their use as proxies for fundamental niches is problematic. The Thermal Neutral Zone for the endotherms, as reported in the GlobTherm database (Bennet et al. 2018) fail to fulfill this criteria, and should not be used as a proxy for the range of positive fitness. On the other hand, the $100 \%$ mortality critical temperatures are indeed represent a fitness range, albeit a bit extreme.

Using the ranges compatible with the concept of fundamental niche, Hutchinson's inequality is proved, adding confirmatory evidence to previous results by Soberon \& Arroyo-Peña (2017). In all the examples we present estimating the fundamental niche with the $100 \%$ 
210 critical range of temperatures, the entire available range of environments occurs inside the

211 fundamental niche. This means that the entire region of hypothetical availability (M) could

212 be occupied. This is certainly not the case, and there are several reasons why there may be

213 empty regions of accessible and favorable space. The first one was proposed by Hutchinson

214 (1957): maybe there are negative interactors (competitors or predators) preventing the

215 expansion of the range of a species. The second one may be the result of using a single

216 variable as a proxy to a multivariate niche. Other variables may be limiting the actual

217 distribution of the species, but we are measuring just one. By adding variables one add

218 constraints to a niche function (Soberón \& Arroyo-Peña, 2017), and therefore reduces the

219 proportion of available environmental space used. The third reason is very similar to the

220 second: unoccupied favorable temperatures may be due to lack of suitable habitat. Habitat,

221 as opposed to climate, may be a limiting factor. For instance, in the case of the freshwater

222 beetles Agabus, climate may be favorable but if the correct type of freshwater body is lacking,

223 the species may not be present. The value of the integrals in table 1 represent the proportion

224 of available climate actually used by the species (assuming the GBIF data is representative).

225 The above point illustrates the need to have a hypothesis about accessible geographic space,

226 or M (Barve et al. 2011). An M hypothesis is not only indispensable when using software

227 sensitive to the background data, like Maxent (VanDerWal, Shoo, Johnson, \& Williams,

228 2009), but also to interpret the results of any niche modeling. Knowledge about the amount

229 of available niche space suggests whether missing factors are present.

230 The work we present here should be regarded as an exploration into the problems of 231 estimating fundamental niches. The main problem is the lack of experimental data, relating 232 many relevant variables to fitness values. This is an obvious problem, and it is very puzzling 233 to notice how little, comparatively, experimental work has been done to address it. Besides 234 temperature physiological ranges, only a handful of experiments include two variables 235 (Birch, 1953; Hooper et al, 2008), and none, to our knowledge, more than 2. This represents 236 an open field of research for the future. 
240 Table 1. Data and occupied niche for the species of beetles and fishes selected.

241 Subjects of study values and characteristics

\begin{tabular}{|c|c|c|c|c|c|c|c|c|c|c|c|}
\hline Species & Tmax & tmin & $\begin{array}{l}\text { Max } \\
\text { Metric } \\
\end{array}$ & $\begin{array}{l}\text { Min } \\
\text { Metric } \\
\end{array}$ & $\begin{array}{l}\text { Niche } \\
\text { width }\end{array}$ & Occurrences & $\begin{array}{l}\text { Clean } \\
\text { Occurrences }\end{array}$ & Phylum & Class & Order & Family \\
\hline $\begin{array}{l}\text { Agabus } \\
\text { brunneus }\end{array}$ & 46.4 & -8.5 & LT100 & LT100 & 0.92 & 1012 & 514 & $\begin{array}{l}\text { Arthropo } \\
\text { da }\end{array}$ & Insecta & Coleoptera & Dytiscidae \\
\hline $\begin{array}{l}\text { Agabus } \\
\text { didymus }\end{array}$ & 44.8 & -9 & LT100 & LT100 & 0.51 & 5313 & 2885 & $\begin{array}{l}\text { Arthropo } \\
\text { da }\end{array}$ & Insecta & Coleoptera & Dytiscidae \\
\hline $\begin{array}{l}\text { Agabus } \\
\text { ramblae }\end{array}$ & 44.5 & -6.8 & LT100 & LT100 & 0.95 & 114 & 114 & $\begin{array}{l}\text { Arthropo } \\
\text { da }\end{array}$ & Insecta & Coleoptera & Dytiscidae \\
\hline $\begin{array}{l}\text { Abudefduf } \\
\text { saxatilis }\end{array}$ & 40 & 10 & LT100 & LT100 & 0.42 & 9989 & 5242 & Chordata & Actinopteri & Perciformes & Pomacentridae \\
\hline $\begin{array}{l}\text { Haemulon } \\
\text { bonariense }\end{array}$ & 40 & 15 & LT100 & LT100 & 0.56 & 120 & 61 & Chordata & Actinopteri & Perciformes & Haemulidae \\
\hline $\begin{array}{l}\text { Lutjanus } \\
\text { apodus }\end{array}$ & 40 & 10 & LT100 & LT100 & 0.27 & 9987 & 6872 & Chordata & Actinopteri & Perciformes & Lutjanidae \\
\hline $\begin{array}{l}\text { Scarus } \\
\text { iseri }\end{array}$ & 35 & 10 & LT100 & LT100 & 0.44 & 9997 & 1796 & Chordata & Actinopteri & Perciformes & Labridae \\
\hline
\end{tabular}

243 Bibliografía

244 Addo-Bediako, A., Chown, S. L., \& Gaston, K. J. (2000). Thermal tolerance, climatic variability and latitude. Proceedings. Biological sciences / The Royal Society, 267(1445), 739-745. https://doi.org/10.1098/rspb.2000.1065

247 Angilletta Jr, M. J., \& Angilletta, M. J. (2009). Thermal adaptation: A theoretical and empirical synthesis. Oxford University Press. 
Birch, L. C. (1953). Experimental Background to the Study of the Distribution and Abundance of Insects: I. The Influence of Temperature, Moisture and Food on the Innate Capacity for Increase of Three Grain Beetles. Ecology, 34(4), 698-711. https://doi.org/10.2307/1931333

Bozinovic, F., Calosi, P., \& Spicer, J. I. (2011). Physiological correlates of geographic range in animals. Annual Review of Ecology, Evolution, and Systematics, 42, 155-179.

Brown, J. H. (1984). On the relationship between abundance and distribution of species. The american naturalist, 124(2), 255-279.

Colwell, R. K., \& Rangel, T. F. (2009). Hutchinson's duality: The once and future niche. Proceedings of the National Academy of Sciences, 106(Supplement_2), 19651-19658. https://doi.org/10.1073/pnas.0901650106

Costello, M. J., \& Wieczorek, J. (2014). Best practice for biodiversity data management and publication. Biological Conservation, 173, 68-73. https://doi.org/10.1016/j.biocon.2013.10.018

Drake, J. M. (2015). Range bagging: A new method for ecological niche modelling from presenceonly data. Journal of the Royal Society Interface, 12(107), 20150086.

Guisan, A., \& Zimmermann, N. E. (2000). Predictive habitat distribution models in ecology. Ecological modelling, 135(2-3), 147-186.

Holt, R. D. (2009). Bringing the Hutchinsonian niche into the 21st century: Ecological and evolutionary perspectives. Proceedings of the National Academy of Sciences, 106(Supplement 2), 19659-19665.

Hooper, H. L., Connon, R., Callaghan, A., Fryer, G., Yarwood-Buchanan, S., Biggs, J., ... Sibly, R. M. (2008). THE ECOLOGICAL NICHE OF DAPHNIA MAGNA CHARACTERIZED USING POPULATION GROWTH RATE. Ecology, 89(4), 1015-1022. https://doi.org/10.1890/070559.1 
273 Hutchinson, G. E. (1957). Concluding remarks Cold Spring Harbor Symposia on Quantitative

Biology, 22: 415-427. GS SEARCH.

275

276

277

278

279

280

281

282

283

Kearney, M., \& Porter, W. (2009). Mechanistic niche modelling: Combining physiological and spatial data to predict species' ranges. Ecology Letters, 12(4), 334-350. https://doi.org/10.1111/j.1461-0248.2008.01277.x

Maguire Jr, B. (1973). Niche response structure and the analytical potentials of its relationship to the habitat. The American Naturalist, 107(954), 213-246.

Peterson, A. T., Soberón, J., Pearson, R. G., Anderson, R. P., Martínez-Meyer, E., Nakamura, M., \& Araújo, M. B. (2011). Ecological niches and geographic distributions Princeton University Press. Princeton, NJ 328pp.

Phillips, S. J., Anderson, R. P., \& Schapire, R. E. (2006). Maximum entropy modeling of species geographic distributions. Ecological modelling, 190(3-4), 231-259.

Robertson, T., Döring, M., Guralnick, R., Bloom, D., Wieczorek, J., Braak, K., ... Desmet, P. (2014). The GBIF Integrated Publishing Toolkit: Facilitating the Efficient Publishing of Biodiversity Data on the Internet. PLOS ONE, 9(8), e102623. https://doi.org/10.1371/journal.pone.0102623

Soberón, J., \& Arroyo-Peña, B. (2017). Are fundamental niches larger than the realized? Testing a 50-year-old prediction by Hutchinson. PLOS ONE, 12(4), e0175138. https://doi.org/10.1371/journal.pone.0175138

VanDerWal, J., Shoo, L. P., Johnson, C. N., \& Williams, S. E. (2009). Abundance and the Environmental Niche: Environmental Suitability Estimated from Niche Models Predicts the Upper Limit of Local Abundance. The American Naturalist, 174(2), 282-291. https://doi.org/10.1086/600087 
bioRxiv preprint doi: https://doi.org/10.1101/716688; this version posted July 28, 2019. The copyright holder for this preprint (which was not certified by peer review) is the author/funder, who has granted bioRxiv a license to display the preprint in perpetuity. It is made available under aCC-BY-ND 4.0 International license. 